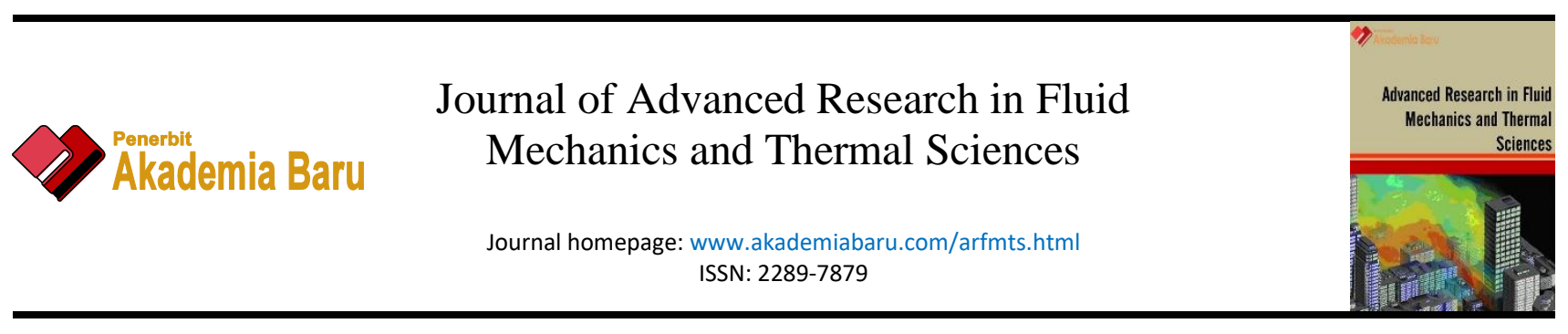

\title{
A Short Review on Novel Membranes for Gas Separation
}

\author{
Muhammad Mufazzal Mustaffa ${ }^{1}$, Norazlianie Sazali ${ }^{1,2,{ }^{*}}$ \\ Faculty of Mechanical \& Automotive Technology Engineering, Universiti Malaysia Pahang, 26600 Pekan, Pahang, Malaysia \\ 2 Centre of Excellence for Advanced Research in Fluid Flow (CARIFF), Universiti Malaysia Pahang, Lebuhraya Tun Razak, 26300 Gambang, \\ Kuantan, Pahang, Malaysia
}

\section{ARTICLE INFO}

\section{Article history:}

Received 5 October 2019

Received in revised form 31 December 2019

Accepted 25 January 2020

Available online 26 April 2020

\section{Keywords:}

Hydrogen membrane separation; carbon

membrane; polymeric membrane;

zeolite molecular sieves; amorphous

silica matrix

\section{ABSTRACT}

\begin{abstract}
The area is a membrane that works faster than any publicly accessible scheme. Membrane technology are more useful than other kinds of membranes for $\mathrm{CO}_{2} / \mathrm{CH}_{4}$ separation, which includes both carbon and zeolite molecular sieves and amorphous silica matrix. Besides, there are several related to the membrane system such as insufficient heat and chemical stability and plasticisation sensitivity. The further improve the transmitter system's position in the separation of gas and economic saving are the advantage of membrane technology to the world. Despite centuries of studies on the topic, fewer than ten polymer kinds are currently used for business gas separation, and no polymer specifically intended for this function. New membrane must deliver substantial rises in $\mathrm{CO}_{2}$ permeance and selectivity of $\mathrm{CO}_{2} / \mathrm{CH}_{4}$ relative to current technologies to contend internationally.
\end{abstract}

\section{Introduction}

The traditional gas separation methods are the advantages offered by the operation of a unit of necessary membrane gas separation [1,2]. Membranes created for hydrogen purification $\left(\mathrm{H}_{2}\right)$ and emphasises the removal of carbon dioxide $\left(\mathrm{CO}_{2}\right)$ from methane $\left(\mathrm{CH}_{4}\right)$. Separating $\mathrm{CO}_{2}$ from natural gas streams is an important industrial process in which it is anticipated that the membrane structure will perform a more significant part in the future. The separation of $\mathrm{CH}_{4}$ and $\mathrm{CO}_{2}$ is vital to the industry especially for natural gas $[3,4]$. Twenty trillion cubic feet of standard natural gas was produced in the US each year, $20 \%$ of these gases require significant treatment $[5,6]$. Besides, there are $70 \%$ of the total gas can be found in $\mathrm{CO}_{2}$ natural gas wells which can lead to erosion and reduce the calorific value of natural gas [7-9]. The US government has decided that the configuration of the tank must below $2 \%$. The benefits of separating membrane gas from traditional methods include small energy

\footnotetext{
* Corresponding author.

E-mail address: azlianie@ump.edu.my (Norazlianie Sazali)
}

https://doi.org/10.37934/arfmts.70.2.111 
consumption, the convenience of use, and modest effect on the environment. Current business plastic cell fluxes and selectivity, however, are too low to handle significant quantities of gas and only small-scale amine factories working under 30 million standard cubes can be damaged by them every day $[10,11]$. Volume relaxation is defined in the form of a slowly increasing amount with time over specific pressures [12]. The membrane must also have outstanding heat and chemical stability, plastic strength (for polymeric membranes), shrinking strength, small price equipment and scale [13]. In the petroleum and chemical processing industries, hydrogen gas is used for various purposes, namely hydrodesulfurization, syngas and ammonia production, Fischer Tropsch synthesis, and for hydrogenation and hydrocracking reactions [14]. $\mathrm{H}_{2}$ is produced worldwide of about $41 \mathrm{MM}$ tons/year [10]. Hence the more efficient and economical $\mathrm{H}_{2}$ separation method is needed for continuous use. The present $\mathrm{H}_{2}$ separation method involves swing stress adsorption, cryogenic distillation, and extraction of membranes. The latter is usually more cost-effective and profitable [1517].

The morphology of the membrane is characterised by electron microscopy screening (SEM). To evaluate the efficiency of membrane separation, gas permeance and selectivity are used. For each cross-membrane pressure, the amount of gas (in the mole) passing through the known membrane area per unit of time is used to represent membrane permeates. The gas permeance the proportion of any two species permeance the membrane and being used as a selectivity test of the removal effectiveness. Also, the literature permeates membrane in some of the systems used to demonstrate consensus and the outcomes recorded in both SI and Barrers branches. Barriers transformed into SI units when the author provides the density of the membrane. The median frequency is used for devices where the recorded density variety is used. Another common gas permeation device is the GPU (carbon permeation device) that can be transformed straight to SI units. Permeance of the value mentioned as Eq. (1):

1 Barrer $=1 \times 10^{-10} \frac{\mathrm{cm}^{3}(\mathrm{STP}) \mathrm{cm}}{\mathrm{cm}^{2} \mathrm{scmHg}}=3.35 \times 10^{-10} \frac{\mathrm{mol}}{\mathrm{m}^{2} \mathrm{sPa}}$,

For a $1 \mu \mathrm{m}$ thickness.

$1 \mathrm{GPU}=1 \times 10^{-6} \frac{\mathrm{cm}^{3}(\mathrm{STP})}{\mathrm{cm}^{2} \mathrm{~s} \mathrm{cmHg}}=3.35 \times 10^{-10} \frac{\mathrm{mol}}{\mathrm{m}^{2} \mathrm{sPa}}$

\section{2. $\mathrm{H}_{2}$ Membrane Separation for Porous Materials}

CVD-prepared silica membranes for $\mathrm{H}_{2}$ separation have been widely researched that provides an overview of the study conducted over the past several years [18-20]. Nearly all the studies reviewed using inorganic $\alpha$-alumina supports that are coated by a single or multiple layer of $\gamma$-alumina $[21,22]$. The permeance of $\mathrm{H}_{2}$ is generally in the order of $10^{-7} \mathrm{~mol} \mathrm{~m}^{-2} \mathrm{~s}^{-1} \mathrm{~Pa}^{-1}$ also $\mathrm{H}_{2}$ selectivity from 70 to 10,000. The silica precursor called TEOS is the most commonly utilized despite the successful use of another type of precursors, for example, phenyltrimethoxysilane (PTMS) and tetramethoxysilane (TMOS) $[23,24] . \mathrm{O}_{2}$ is mostly used as an oxidizing agent to encourage decomposition of the silica precursor; however, it has been stated that the decomposition of the silica precursor occurs in an inert atmosphere $[25,26]$. Figure 1 shows membrane reactor for hydrogen production from natural gas at the Tokyo Gas Company [27]. 
(a)

(b)

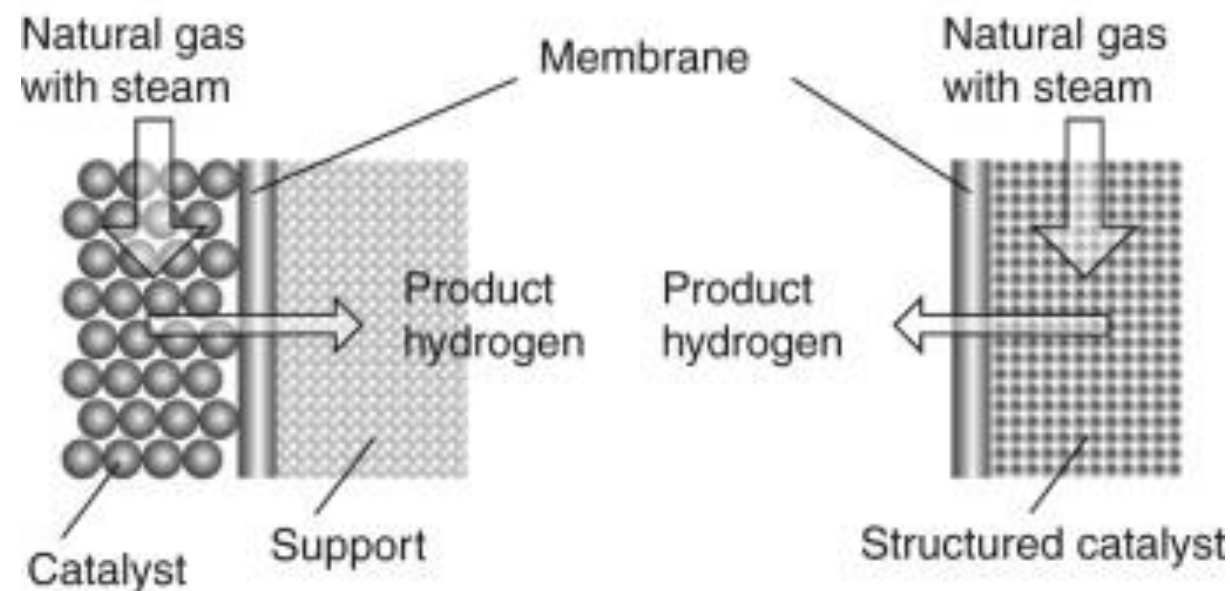

Fig. 1. Membrane reactor for hydrogen production from natural gas at the Tokyo Gas Company [27]

Hollow fibers are leading compared to the traditional ceramic tubular membranes due to the properties of high ratio of area to volume. Hollow fiber can be mounted into multi-tube reactors that will improve the use of volume. The silica separation layer has been discovered to be deposited on the outside of the fiber in all the report mentioned [28]. It is useful in separation but cannot be used in catalytic membrane reactors due to abrasion issues resulting from the contact between the permselective layers with the catalyst pellets. A more in-depth investigation of the outcomes stated in all but two research in the literature seems to have evacuated reactants through the pore walls during the CVD implementation [19]. Vacuum application is asserted to enhance the coverage of silica deposition defects [29]. Studies stated that, if an intermediate layer of $\gamma$-alumina is applied to the $\alpha$-alumina substrate before CVD, the $\mathrm{H}_{2}$ permeance is improved by an order of magnitude approximately [30]. The molar flow rate of silica precursor varied by more than two orders of magnitude but there was no evaluation of the impacts on $\mathrm{H}_{2}$ permeance or selectivity. Three of the researches used $\mathrm{O}_{2}$ or $\mathrm{O}_{3}$, which functions as an oxidant to encourage decomposition in membrane pores of the silica precursor [31-33]. The implementation of the oxidant reagent gives a significant impact of increasing the final $\mathrm{H}_{2}$ permeance than the research based on only the thermal decomposition of the silica precursor.

\section{3. $\mathrm{CO}_{2} / \mathrm{CH}_{4}$ Membrane Separation}

The present $\mathrm{CO}_{2}$ separation method on porous inorganic assistance, amorphous silica substrates, fiber substrates, blended medium substrates, and RTIL membranes includes zeolites and carbon molecular sieve. Literary reports published in recent years are used to review these systems $[6,34,35]$. Zeolite is a pore-structured aluminosilicate. In general, zeolite covers consist of a thin coating of several micrometres of zeolite placed on a covering such as tubular metal or porous $\alpha$ alumina. Excellent heat and mechanical strength and chemical resistance are among the benefits that this membrane provides over traditional polymer gas separation membranes [36,37]. The separation of zeolite membranes is accomplished through molecular sieving with surface diffusion. The traps forming the zeolite's pore framework have the capacity to distinguish liquids depending on their kinetic diameter. Due to preferential adsorption in $\mathrm{CO}_{2}$ instances, separation is increased at reduced temperatures [38]. Previous research showed the excellent results for both selectivity and permeance for the zeolite membrane [39]. Zeolite membranes supported by either stainless steel or 
$\alpha$-alumina showed the highest values for both permeance $\mathrm{CO}_{2}$ and selectivity of $\mathrm{CO}_{2} / \mathrm{CH}_{4}$. Carreon and co-workers are able to synthesize SAPO-34 zeolite membranes on porous $\alpha$-alumina support with permeance $\mathrm{CO}_{2} 1.0-2.0 \times 10-6 \mathrm{~mol} \mathrm{m-2} \mathrm{s-1} \mathrm{Pa-1}$ and $\mathrm{CO}_{2} / \mathrm{CH}_{4}$ selectivity 86-171 [40]. SAPO $\mathrm{CO}_{2-}$ permeance membranes $3.9 \times 10-8-2.0 \times 10-7$ mol m-2 s-1 Pa-1 and $\mathrm{CO}_{2} / \mathrm{CH}_{4}$ selectivity $32-118$ described by two other accounts from the same study unit. The membrane is ready on the backing, a porous stainless-steel pipe, by crystallization in situ.

Furthermore, the DDR-type zeolite fibers constitute extremely hydrophobic assistance on $\alpha$ alumina with $2.9 \times 10-7 \mathrm{~mol} \mathrm{~m}-2 \mathrm{~s}-1 \mathrm{~Pa}-1 \mathrm{CO}_{2}$ permeable and more than $400 \mathrm{CO}_{2} / \mathrm{CH}_{4}$ selectivities at house temperature [41]. Overall, in comparison with traditional polymer membranes, zeolite membranes demonstrate an enhancement in the design of gas separation. This can be ascribed to the present existence of transportation of zeolite gas. The zeolites have a transparent porous network, and if the membrane separation layer is thin, high gas dependency can be achieved. In gas zeolite membranes, size exclusion and selective adsorption are segregated, resulting in more excellent selectivity following the dispersion process than polymer membranes. Zeolite does not show plasticization until even at elevated concentrations, the selectivity of $\mathrm{CO}_{2} / \mathrm{CH}_{4}$ is outstanding. Unlike polymeric membranes, zeolite fibers can resist comparatively high pressures in the existence of oxygen. It is essential that $\mathrm{CO}_{2} / \mathrm{CH}_{4}$ choice with temperature declines owing to reduced specific $\mathrm{CO}_{2}$ adsorption. Also, high cost, hard to process, and hard to manage, offsetting some of their appealing characteristics of separation. Commercial implementation cannot take place until the cost of the zeolite membrane is lowered by a percentage of 10 [42]. Figure 2 shows High-flux CHA zeolite membranes for $\mathrm{H}_{2}$ separations [43].

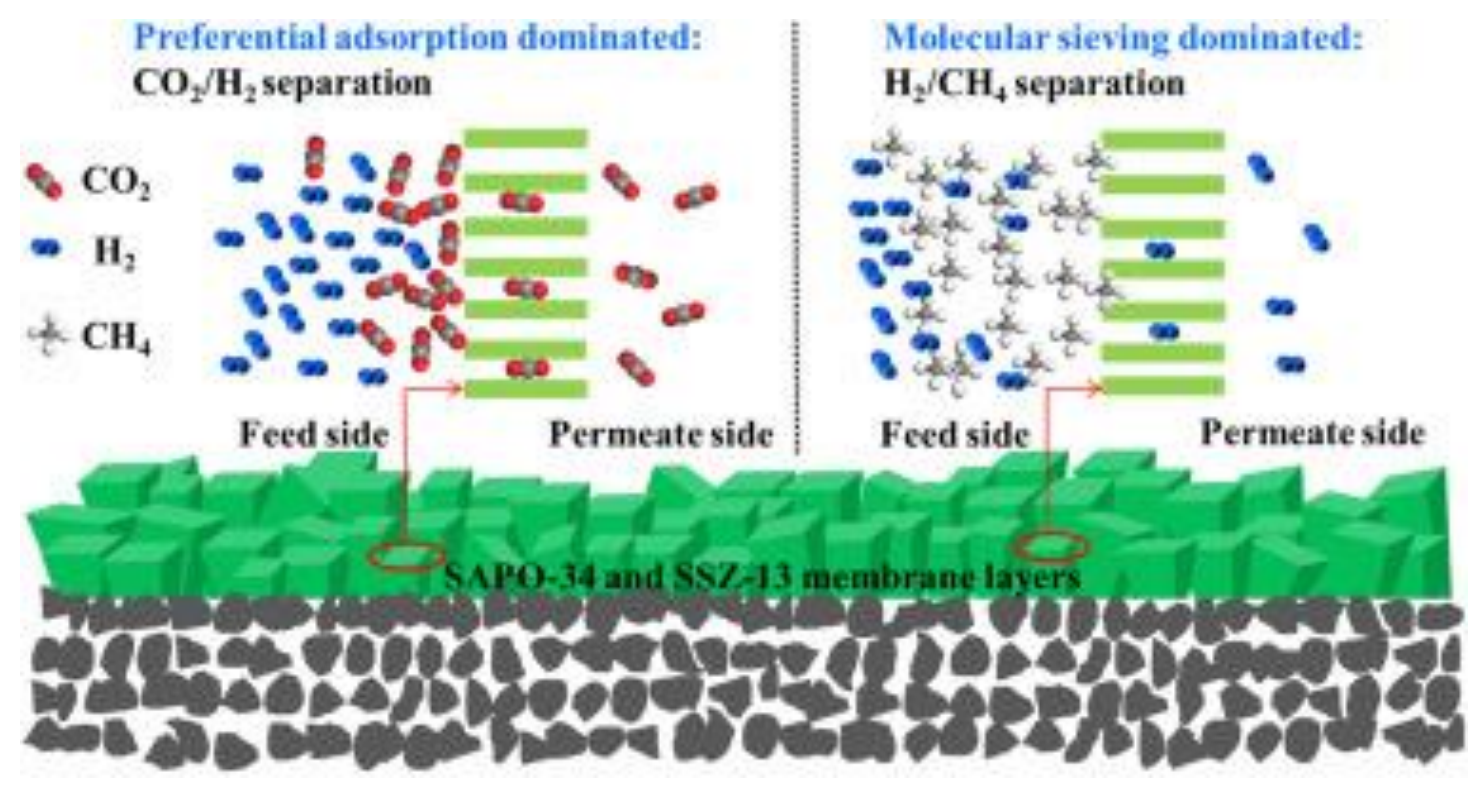

Fig. 2. High-flux $\mathrm{CHA}$ zeolite membranes for $\mathrm{H}_{2}$ separations [43]

Carbon membranes are random porous networks that are generated under regulated circumstances by thermosensitive polymer thermosets and have excellent heat and chemical stability [44]. Pyrolysis produces layers with a molecular aspect (molecular sieve) allocation of the small pore volume. Depending on the preparation circumstance, the pore magnitude in carbon fibers used to separate the gas ranges from 0.35 to $1 \mathrm{~nm}$ [45]. Pore construct can be defined as a comparatively big gap comparable in volume to the gas molecules in the "tight" throat. The primary mechanism of gas transport is the diffusion of molecules where smaller dimensional particles are absorbed by choice compared to larger dimensional particles [46]. More substantial molecule permeability is strictly 
sterically restricted while permeation of smaller molecules of a specific size occurs faster. The interaction of the gas molecules with the walls of the carbon molecular sieve made up of two teams that repulsive and attractive. The gas molecule is required to overcome the activation energy barrier that results from the rejection force passing through the pore opening. The significant changes in permeance caused by small changes in the size of the molecule can be explained by the diffusion activated through the membrane. The second mechanism of transport in the carbon membrane is associated with surface diffusion with selective adsorption. Carbon membrane, which depends on the particular surface diffusion mechanism, generally has a larger pore size and is capable of separating highly adsorbent gas $\left(\mathrm{NH}_{3}, \mathrm{CO}_{2}, \mathrm{H} 2 \mathrm{~S}\right)$ from the adsorbent gas $\left(\mathrm{CH}_{4}, \mathrm{O}_{2}, \mathrm{~N}_{2}\right)$ and can either be supported (on tube or flat) or not supported [47]. Unsupported carbon membranes (flat or tubular) are fragile and difficult to maintain, and, moreover, thicker than supported membranes and thus exhibit lower gas permeability. Carbon membrane supported permeates better showcase for decreasing the thickness of the active layer, which reduces the resistance to gas flow - carbon molecular sieve membranes displaying excellent properties of separation $\mathrm{CO}_{2} / \mathrm{CH}_{4}$.

Yoshimune and Kenji [48] synthesized unsupported carbon membranes. The results show that the selectivity of $\mathrm{CO}_{2} / \mathrm{CH}_{4}$ are very high 100-130 but low permeance $(2.8 \times 10-9-7.5 \times 10-9 \mathrm{~mol} \mathrm{~m}-2 \mathrm{~s}$ $1 \mathrm{~Pa}-1)$. This phenomenon is due to the high membrane thickness (23-25 m) [48]. Jiang et al., [49] synthesized double-layer hollow membranes on Matrimid support. The emission of $\mathrm{CO}_{2}$ on this membrane was relatively low $(4.2 \times 10-9$ mol m-2 s-1 Pa-1) due to the collapse of micropores in the support layer, but $\mathrm{CO}_{2} / \mathrm{CH}_{4}$ selectivity was high [49]. Membrane selectivity is impaired in the thin layer of carbon separation $(1 \mu \mathrm{m})$ supported on $\alpha$-alumina, but nonetheless, the results are promising. The thin layer of active carbon separation must be defect-free if the membrane selectivity is significantly reduced. The carbon membrane has many of the same problems as the zeolite membrane. Instead, they are costly, hard to process, and hard to manage. Other disadvantages include the susceptibility of carbon membranes to oxidizing agents and the degradation of water vapour over time $[50,51]$. The synthesized stable carbon membranes, required to have technology accessible first to create excellent polymeric membranes. Under very narrow circumstances, polymeric substrates must be pyrolyzed, which can be hard to enhance. The amorphous and mesoporous membranes are the two types of silica membrane that can be split by membrane morphology. In cases of amorphous silica, or claims of mesoporous silica, these membranes are usually generated by CVD or sol-gel synthesis from silica precursors or by sol-gel or hydrothermal synthesis. CVD-prepared membrane using conventional silica precursors like TEOS or tetramethyl orthosilicate (TMOS) usually produces a small silica microporous or nonporous film appropriate for $\mathrm{H}_{2}$ or He separation [29]. In relatively small gas molecules, these membranes are very soluble, but the permeability of bigger gas molecules such as $\mathrm{CO}_{2}$ is very low. It is essential to use silica precursors comprising significant organic components, such as phenyl clusters, to attain greater $\mathrm{CO}_{2}$ absorption levels through the CVD process. Two types of research investigated here using phenyl-containing precursors that form a tight silica-packed porous framework relative to normal CVD [52]. The mesoporous membrane provided by the sol-gel technique has a clear pore structure and acts as a molecular sieve. Sol-gel pathways are an easy way to produce silica layers, but the final morphology of the membrane is highly dependent on the synthesis parameters. This enables monitoring of the exact pore morphology and composition, but also makes the ultimate membrane susceptible to synthesis circumstances and thus hard to replicate. In particular, more significant emissions in solgel-prepared membranes are much greater in the CVD membrane relative to CVD, but membrane stabilization and film durability [18]. 


\section{Polymeric Membranes}

The organic polymer is the material most commonly used in gas separation membranes [53]. The polymer can be split into two groups, i.e. running above crystal transfer temperature (a plastic polymer) and working below crystal transfer rate (crystal polymer). Polymer glasses can efficiently distinguish molecules depending on tiny variations in molecule dimensions [54]. In the magnitude and structure of the rubber polymer, they are more competitive and therefore, more appropriate for $\mathrm{CO}_{2}$ separation. According to Henry's law of gas absorption in rubber polymer; the absorption in glass polymers can be described by the complicated absorption isotherms connected with the unabsorbed size of the matrix when discharged under the glass transition temperature. Complete details of solubility can be discovered elsewhere in glass polymers [55]. Commercial polymer membranes have asymmetric constructions that are usually backed by porous materials with tiny specific strands. The thicker backing layer guarantees the structure's stability while the thinner protective coating enables higher flux of gas through the membrane. Recently papers on technologies that mix various polymers. In the case of mixed membranes, glass polymers are covered with high diffusivity in a matrix of rubber polymer to incorporate high selectivity from the latter [56]. Besides, the glassy polymer provides mechanical support to the matrix structure and rubber [57]. The polymer membranes are not porous and gas permeation mechanism administered by the deployment of the solution. Therefore, the mechanism was by the solubility in the polymer matrix [58]. The gas molecules absorb from the portion of the feed into the gas membrane interface, dissolving and absorbing the molecules through the membrane with random dispersion. Dissemination happens between polymer chains in freevolume components ( 0.2 and $0.5 \mathrm{~nm}$ in length) that occur and continually vanish owing to thermal motion.

The dispersion of gases through the naturally non-porous polymeric structure is slow, and thus the polymer membrane exhibits low $\mathrm{CO}_{2}$ permeance with moderate $\mathrm{CO}_{2} / \mathrm{CH}_{4}$ selectivity. Polymer membranes now monopolize the market due to low material cost and processing facilities [54]. Compared with other membrane systems described above, the polymer membrane is more comfortable to handle more than the critical current scale. The polymer membrane systems studied in this chapter generally exhibit permeances below $1 \times 10-8 \mathrm{~mol} \mathrm{~m}-2 \mathrm{~s}-1 \mathrm{~Pa}-1$. The reduced gas permeability of the polymer membrane can be understood from the gas diffusion mechanism. Permeance is naturally low because gas must dissolve in and absorb through non-porous solids. Also, there is a well-known trade-off between the selectivity and permeance for polymer membranes. Despite intense research on membrane gas separation in recent years, polymer membranes have not been able to progress beyond the "line of death" called the Robeson plot which describes the precision selections in polymer membranes.

\section{Mixed Matrix Membranes}

Organic-inorganic membrane consisting of a mixture of inorganic particles. Mixed matrix membranes attempt to mix the handling of polymeric materials with outstanding molecular sieve vapour separation properties [59]. Gas transferred through the inorganic and polymer stage. Inorganic ions may behave as molecular sieves. Transportation happens primarily through the inorganic stage at very elevated inorganic load. There are also blended matrix membranes that depend on inorganic fillers, selectively absorbing various gases [36]. According to Suzuki and Yasuharu [60] the suitable option for $\mathrm{CO}_{2} / \mathrm{CH}_{4}$ of 54-95 was 6FDA-TAPOB modified hyperbranched polyimide - silica hybrid with tetramethoxysilane as a precursor. The mixed matrix membrane regime $\mathrm{CO}_{2}$ permeance investigated in this section usually drops below $1 \times 10-8 \mathrm{~mol} \mathrm{~m}-2 \mathrm{~s}-1 \mathrm{~Pa}-1$. There was 
no vital rise in $\mathrm{CO}_{2} / \mathrm{CH}_{4}$ selectivity over a polymer membrane in the general composite membrane of organic-inorganic.

\section{Conclusions}

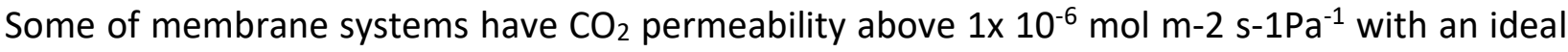
$\mathrm{CO}_{2} / \mathrm{CH}_{4}$ choice above 100 . The findings achieved with PTES thermal decomposition binary organicinorganic silica membranes show that these membranes function well in comparison with other kinds of membranes. For comparison, low $\mathrm{CO}_{2}$ permeances in the range of $1 \times 10-11$ to $1 \times 10-8 \mathrm{~mol} \mathrm{~m}-2 \mathrm{~s}-$ $1 \mathrm{~Pa}-1$ and $\mathrm{CO}_{2} / \mathrm{CH}_{4}$ selectivity between 15 and 100 were shown by organic membranes (polymeric). Mixed matrix membranes showed no significant increase in $\mathrm{CO}_{2}$ separation compared to polymeric membranes. The $\mathrm{CO}_{2}$ surface is usually less than $1 \times 10-9 \mathrm{~mol} \mathrm{~m}-2 \mathrm{~s}-1 \mathrm{~Pa}-1$, and the ideal $\mathrm{CO}_{2} / \mathrm{CH}_{4}$ choice is less than 100. Compared to other membrane separation technologies, supported ionic liquid substrates demonstrate lower $\mathrm{CO}_{2} / \mathrm{CH}_{4}$ separation efficiency. Overall, the $\mathrm{CO}_{2}$ permeance backed by ionic liquid filters is more significant than polymer matrix or blended, but the selectivity of $\mathrm{CO}_{2} /$ $\mathrm{CH}_{4}$ is low.

\section{Acknowledgment}

The authors would like to acknowledge the financial support from the Ministry of Higher Education and Universiti Malaysia Pahang (UMP) with grant number RDU192315.

\section{References}

[1] Sazali, Norazlianie, Wan Norharyati Wan Salleh, Ahmad Fauzi Ismail, Nor Hafiza Ismail, and Kumaran Kadirgama. "A brief review on carbon selective membranes from polymer blends for gas separation performance." Reviews in Chemical Engineering 1, no. ahead-of-print (2019).

https://doi.org/10.1515/revce-2018-0086

[2] Rezakazemi, Mashallah, Mohtada Sadrzadeh, and Takeshi Matsuura. "Thermally stable polymers for advanced high-performance gas separation membranes." Progress in Energy and Combustion Science 66 (2018): 1-41. https://doi.org/10.1016/i.pecs.2017.11.002

[3] Sunarso, J., Siti Salwa Hashim, Y. S. Lin, and S. M. Liu. "Membranes for helium recovery: An overview on the context, materials and future directions." Separation and Purification Technology 176 (2017): 335-383.

https://doi.org/10.1016/j.seppur.2016.12.020

[4] Popov, Dimityr, Kostadin Fikiin, Borislav Stankov, Graciela Alvarez, Mohammed Youbi-Idrissi, Alain Damas, Judith Evans, and Tim Brown. "Cryogenic heat exchangers for process cooling and renewable energy storage: A review." Applied Thermal Engineering 153 (2019): 275-290. https://doi.org/10.1016/i.applthermaleng.2019.02.106

[5] Mahdyarfar, Mohammad, Toraj Mohammadi, and Ali Mohajeri. "Gas separation performance of carbon materials produced from phenolic resin: Effects of carbonization temperature and ozone post treatment." New Carbon Materials 28, no. 1 (2013): 39-46. https://doi.org/10.1016/S1872-5805(13)60063-3

[6] Ravanchi, Maryam Takht, Tahereh Kaghazchi, and Ali Kargari. "Application of membrane separation processes in petrochemical industry: a review." Desalination 235, no. 1-3 (2009): 199-244. https://doi.org/10.1016/j.desal.2007.10.042

[7] Sazali, N., W. N. W. Salleh, A. F. Ismail, K. Kadirgama, F. E. C. Othman, and N. H. Ismail. "Impact of stabilization environment and heating rates on P84 co-polyimide/nanocrystaline cellulose carbon membrane for hydrogen enrichment." International Journal of Hydrogen Energy 44, no. 37 (2019): 20924-20932. https://doi.org/10.1016/j.ijhydene.2018.06.039

[8] Sazali, N., W. N. W. Salleh, A. F. Ismail, N. H. Ismail, F. Aziz, N. Yusof, and H. Hasbullah. "Effect of stabilization temperature during pyrolysis process of P84 co-polyimide-based tubular carbon membrane for H2/N2 and He/N2 separations." In IOP Conference Series: Materials Science and Engineering, vol. 342, no. 1, p. 012027. IOP Publishing, 2018.

https://doi.org/10.1088/1757-899X/342/1/012027 
[9] Alders, Michael, Dominik Winterhalder, and Matthias Wessling. "Helium recovery using membrane processes." Separation and Purification Technology 189 (2017): 433-440.

https://doi.org/10.1016/i.seppur.2017.07.084

[10] Liang, Can Zeng, Tai-Shung Chung, and Juin-Yih Lai. "A review of polymeric composite membranes for gas separation and energy production." Progress in Polymer Science 97 (2019): 101141. https://doi.org/10.1016/i.progpolymsci.2019.06.001

[11] Gray, Narges, Yahya Hamzeh, Alireza Kaboorani, and Ali Abdulkhani. "Influence of cellulose nanocrystal on strength and properties of low density polyethylene and thermoplastic starch composites." Industrial Crops and Products 115 (2018): 298-305. https://doi.org/10.1016/i.indcrop.2018.02.017

[12] Chen, J., Leslie S. Loo, K. Wang, and D. D. Do. "The structural characterization of a CMS membrane using Ar sorption and permeation." Journal of Membrane Science 335, no. 1-2 (2009): 1-4. https://doi.org/10.1016/j.memsci.2009.03.008

[13] Kanehashi, Shinji, George Q. Chen, David Danaci, Paul A. Webley, and Sandra E. Kentish. "Can the addition of carbon nanoparticles to a polyimide membrane reduce plasticization?." Separation and Purification Technology 183 (2017): 333-340. https://doi.org/10.1016/i.seppur.2017.04.013

[14] Mahurin, Shannon M., Je Seung Lee, Xiqing Wang, and Sheng Dai. "Ammonia-activated mesoporous carbon membranes for gas separations." Journal of Membrane Science 368, no. 1-2 (2011): 41-47. https://doi.org/10.1016/i.memsci.2010.11.007

[15] Anderson, Thomas R., Ed Hawkins, and Philip D. Jones. "CO2, the greenhouse effect and global warming: from the pioneering work of Arrhenius and Callendar to today's Earth System Models." Endeavour 40, no. 3 (2016): $178-187$. https://doi.org/10.1016/i.endeavour.2016.07.002

[16] Marczewski, M., E. Kamińska, H. Marczewska, M. Godek, G. Rokicki, and J. Sokołowski. "Catalytic decomposition of polystyrene. The role of acid and basic active centers." Applied Catalysis B: Environmental 129 (2013): 236-246. https://doi.org/10.1016/i.apcatb.2012.09.027

[17] Makaruk, A., M. Miltner, and M. Harasek. "Biogas desulfurization and biogas upgrading using a hybrid membrane system-modeling study." Water Science and Technology 67, no. 2 (2013): 326-332. https://doi.org/10.2166/wst.2012.566

[18] Czympiel, Lisa, Michael Frank, Andreas Mettenbörger, Sven-Martin Hühne, and Sanjay Mathur. "High activity heterogeneous catalysts by plasma-enhanced chemical vapor deposition of volatile palladium complexes on biomorphic carbon." Comptes Rendus Chimie 21, no. 10 (2018): 943-951. https://doi.org/10.1016/i.crci.2018.04.008

[19] Cheng, Li-Hua, Ywu-Jang Fu, Kuo-Sung Liao, Jung-Tsai Chen, Chien-Chieh Hu, Wei-Song Hung, Kueir-Rarn Lee, and Jui-Yih Lai. "A high-permeance supported carbon molecular sieve membrane fabricated by plasma-enhanced chemical vapor deposition followed by carbonization for CO2 capture." Journal of Membrane Science 460 (2014): 1-8.

https://doi.org/10.1016/i.memsci.2014.02.033

[20] Zhang, Y., J. A. Haynes, B. A. Pint, I. G. Wright, and W. Y. Lee. "Martensitic transformation in CVD NiAl and (Ni, Pt) Al bond coatings." Surface and Coatings Technology 163 (2003): 19-24. https://doi.org/10.1016/S0257-8972(02)00585-6

[21] Guo, Yu, Hongmei Wu, Yujia Jin, Lidai Zhou, Qiangqiang Chen, and Xianfeng Fan. "Deposition of TS-1 zeolite film on palladium membrane for enhancement of membrane stability." International Journal of Hydrogen Energy 42, no. 44 (2017): 27111-27121.

https://doi.org/10.1016/j.ijhydene.2017.09.127

[22] Zainal, Wan Nurul Huda Wan, Soon Huat Tan, and Mohd Azmier Ahmad. "Carbon membranes prepared from a polymer blend of polyethylene glycol and polyetherimide." Chemical Engineering \& Technology 40, no. 1 (2017): 94-102. https://doi.org/10.1002/ceat.201500752

[23] Lau, Cher Hon, Phuc Tien Nguyen, Matthew R. Hill, Aaron W. Thornton, Kristina Konstas, Cara M. Doherty, Roger J. Mulder et al. "Ending aging in super glassy polymer membranes." Angewandte Chemie International Edition 53, no. 21 (2014): 5322-5326. https://doi.org/10.1002/anie.201402234

[24] Ahmad, Z., N. A. Al-Awadi, and F. Al-Sagheer. "Thermal degradation studies in poly (vinyl chloride)/poly (methyl methacrylate) blends." Polymer Degradation and Stability 93, no. 2 (2008): 456-465. https://doi.org/10.1016/i.polymdegradstab.2007.11.019 
[25] Wan, Junjie, Xin Feng, Yu Li, Jinqiang He, Na Zhao, Zhifeng Liu, Yajing Lin, Chuangxin Yang, and Wanqi Liang. "Effect of mesoporous silica molecular sieve coating on nZVI for 2, 4-DCP degradation: Morphology and mechanism during the reaction." Chemical Engineering and Processing-Process Intensification 135 (2019): 68-81.

https://doi.org/10.1016/i.cep.2018.11.011

[26] Shafie, Siti Nur Alwani, Wen Xuan Liew, Md Nordin, Nik Abdul Hadi, Muhammad Roil Bilad, Norazlianie Sazali, Zulfan Adi Putra, and Mohd Dzul Hakim Wirzal. "CO2-Philic [EMIM][Tf2N] Modified Silica in Mixed Matrix Membrane for High Performance CO2/CH4 Separation." Advances in Polymer Technology 2019 (2019).

https://doi.org/10.1155/2019/2924961

[27] Shirasaki, Y., and I. Yasuda. "Membrane reactor for hydrogen production from natural gas at the Tokyo Gas Company: a case study." In Handbook of Membrane Reactors, pp. 487-507. Woodhead Publishing, 2013.

https://doi.org/10.1533/9780857097347.2.487

[28] Zhao, Yayun, Dechuan Zhao, Chunlong Kong, Feng Zhou, Tengyao Jiang, and Liang Chen. "Design of thin and tubular MOFs-polymer mixed matrix membranes for highly selective separation of $\mathrm{H} 2$ and CO2." Separation and Purification Technology 220 (2019): 197-205.

https://doi.org/10.1016/i.seppur.2019.03.037

[29] Chen, Pei, Xinbing Chen, Xiangshu Chen, Zhongwei An, and Hidetoshi Kita. "Pervaporation Separation and Catalysis Activity of Novel Zirconium Silicalite-1 Zeolite Membrane." Chinese Journal of Chemistry 27, no. 9 (2009): 16921696. https://doi.org/10.1002/cjoc.200990284

[30] Tseng, Hui-Hsin, Ching-Ting Wang, Guo-Liang Zhuang, Petr Uchytil, Jirina Reznickova, and Katka Setnickova. "Enhanced $\mathrm{H} 2 / \mathrm{CH} 4$ and $\mathrm{H} 2 / \mathrm{CO} 2$ separation by carbon molecular sieve membrane coated on titania modified alumina support: Effects of $\mathrm{TiO} 2$ intermediate layer preparation variables on interfacial adhesion." Journal of Membrane Science 510 (2016): 391-404.

https://doi.org/10.1016/i.memsci.2016.02.036

[31] Ji, Guozhao, Anthe George, Vicky Skoulou, Graham Reed, Marcos Millan, Kamel Hooman, Suresh K. Bhatia, and João C. Diniz da Costa. "Investigation and simulation of the transport of gas containing mercury in microporous silica membranes." Chemical Engineering Science 190 (2018): 286-296. https://doi.org/10.1016/i.ces.2018.06.006

[32] Wu, Wanhao, Qian Yang, and Bin Su. "Centimeter-scale continuous silica isoporous membranes for molecular sieving." Journal of Membrane Science 558 (2018): 86-93.

https://doi.org/10.1016/j.memsci.2018.04.024

[33] Zhuang, Guo-Liang, Ming-Yen Wey, and Hui-Hsin Tseng. "The density and crystallinity properties of PPO-silica mixed-matrix membranes produced via the in situ sol-gel method for $\mathrm{H} 2 / \mathrm{CO} 2$ separation. II: Effect of thermal annealing treatment." Chemical Engineering Research and Design 104 (2015): 319-332. https://doi.org/10.1016/i.cherd.2015.08.020

[34] Lu, G. Q., JC Diniz Da Costa, Mikel Duke, S. Giessler, R. Socolow, R. H. Williams, and T. Kreutz. "Inorganic membranes for hydrogen production and purification: a critical review and perspective." Journal of Colloid and Interface Science 314, no. 2 (2007): 589-603. https://doi.org/10.1016/j.jcis.2007.05.067

[35] Kim, Seong-Joong, Pyung Soo Lee, Jong-San Chang, Seung-Eun Nam, and You-In Park. "Preparation of carbon molecular sieve membranes on low-cost alumina hollow fibers for use in C3H6/C3H8 separation." Separation and Purification Technology 194 (2018): 443-450.

https://doi.org/10.1016/i.seppur.2017.11.069

[36] Feng, C., K. C. Khulbe, T. Matsuura, R. Farnood, and A. F. Ismail. "Recent progress in zeolite/zeotype membranes." Journal of Membrane Science and Research 1, no. 2 (2015): 49-72.

[37] Al-Dughaither, Abdullah S., and Hugo de Lasa. "HZSM-5 zeolites with different SiO2/Al2O3 ratios. Characterization and NH3 desorption kinetics." Industrial \& Engineering Chemistry Research 53, no. 40 (2014): 15303-15316. https://doi.org/10.1021/ie4039532

[38] Lee, Jinwoo, Jaeyun Kim, and Taeghwan Hyeon. "Recent progress in the synthesis of porous carbon materials." Advanced Materials 18, no. 16 (2006): 2073-2094.

https://doi.org/10.1002/adma.200501576

[39] Van den Bergh, J., W. Zhu, J. Gascon, J. A. Moulijn, and F. Kapteijn. "Separation and permeation characteristics of a DD3R zeolite membrane." Journal of Membrane Science 316, no. 1-2 (2008): 35-45. https://doi.org/10.1016/i.memsci.2007.12.051

[40] Carreon, Moises A., Shiguang Li, John L. Falconer, and Richard D. Noble. "Alumina-supported SAPO-34 membranes for CO2/CH4 separation." Journal of the American Chemical Society 130, no. 16 (2008): 5412-5413. https://doi.org/10.1021/ja801294f 
[41] Betke, Ulf, and Alexandra Lieb. "Micro-Macroporous Composite Materials-Preparation Techniques and Selected Applications: A Review." Advanced Engineering Materials 20, no. 9 (2018): 1800252.

https://doi.org/10.1002/adem.201800252

[42] Zito, Pasquale F., Alessio Caravella, Adele Brunetti, Enrico Drioli, and Giuseppe Barbieri. "Knudsen and surface diffusion competing for gas permeation inside silicalite membranes." Journal of Membrane Science 523 (2017): 456-469. https://doi.org/10.1016/i.memsci.2016.10.016

[43] Mei, Weiliang, Yang Du, Tangyan Wu, Feng Gao, Bin Wang, Jingui Duan, Junjing Zhou, and Rongfei Zhou. "High-flux CHA zeolite membranes for H2 separations." Journal of Membrane Science 565 (2018): 358-369. https://doi.org/10.1016/i.memsci.2018.08.025

[44] Zhang, Bing, Lin Li, Chunlei Wang, Jing Pang, Shouhai Zhang, Xigao Jian, and Tonghua Wang. "Effect of membranecasting parameters on the microstructure and gas permeation of carbon membranes." RSC Advances 5, no. 74 (2015): 60345-60353. https://doi.org/10.1039/C5RA10473D

[45] Li, H., K. Haas-Santo, U. Schygulla, and R. Dittmeyer. "Inorganic microporous membranes for H2 and CO2 separation-Review of experimental and modeling progress." Chemical Engineering Science 127 (2015): 401-417. https://doi.org/10.1016/i.ces.2015.01.022

[46] Ismail, N. H., W. N. W. Salleh, N. Sazali, and A. F. Ismail. "Effect of intermediate layer on gas separation performance of disk supported carbon membrane." Chemical Engineering Transactions 45 (2015), 14651470 . https://doi.org/10.3302/cet1545245

[47] Sazali, Norazlianie, Salleh W. N. W., Ahmad Fauzi Ismail, Nor Hafiza Ismail, Norhaniza Yusof, Farhana Aziz, Juhana Jaafar, and Nordin N. A. H. M. "Controlled Dip-coating Times for Improving CO2 Selective of PI/NCCbased Supported Carbon Membrane." Journal of Membrane Science and Technology 8, no. 1 (2018): 1-5.

[48] Yoshimune, Miki, and Kenji Haraya. "CO2/CH4 mixed gas separation using carbon hollow fiber membranes." Energy Procedia 37, no. 0 (2013): 1109-1116. https://doi.org/10.1016/i.egypro.2013.05.208

[49] Jiang, Lan Ying, Tai Shung Chung, and Santi Kulprathipanja. "Fabrication of mixed matrix hollow fibers with intimate polymer-zeolite interface for gas separation." AIChE Journal 52, no. 8 (2006): 2898-2908. https://doi.org/10.1002/aic.10909

[50] Uhlhorn, R. J. R., Klaas Keizer, and A. J. Burggraaf. "Gas and surface diffusion in modified $\gamma$-alumina systems." Journal of Membrane Science 46, no. 2-3 (1989): 225-241. https://doi.org/10.1016/S0376-7388(00)80337-3

[51] Alamaria, Abdulhakim M., M. G. Mohd Nawawi, and Zafifah Zamrud. "Chemical cross-linking of sago/PVA blend membrane for pervaporation separation of water from ethyl acetate mixture." Journal of Advanced Research in Materials Science 1, no. 1 (2014): 14-21.

[52] Salleh, Muhammad Taufiq, Juhana Jaafar, Mohamad Azuwa Mohamed, M. N. A. M. Norddin, A. F. Ismail, M. H. D. Othman, Mukhlis A. Rahman, N. Yusof, F. Aziz, and W. N. W. Salleh. "Stability of SPEEK/Cloisite ${ }^{\circledR / T A P}$ nanocomposite membrane under Fenton reagent condition for direct methanol fuel cell application." Polymer Degradation and Stability 137 (2017): 83-99.

https://doi.org/10.1016/i.polymdegradstab.2016.12.011

[53] Pulido, B. A., Christopher Waldron, M. G. Zolotukhin, and Suzana Pereira Nunes. "Porous polymeric membranes with thermal and solvent resistance." Journal of Membrane Science 539 (2017): 187-196. https://doi.org/10.1016/i.memsci.2017.05.070

[54] Bounaceur, Roda, Etienne Berger, Marc Pfister, Alvaro Andres Ramirez Santos, and Eric Favre. "Rigorous variable permeability modelling and process simulation for the design of polymeric membrane gas separation units: MEMSIC simulation tool." Journal of Membrane Science 523 (2017): 77-91. https://doi.org/10.1016/i.memsci.2016.09.011

[55] Khurma, Jagjit R., David R. Rohindra, and Ranjani Devi. "Miscibility study of solution cast blends of poly (lactic acid) and poly (vinyl butyral)." The South Pacific Journal of Natural and Applied Sciences 23, no. 1 (2005): 22-25. https://doi.org/10.1071/SP05004

[56] Yampolskii, Yuri. "Polymeric gas separation membranes." Macromolecules 45, no. 8 (2012): 3298-3311. https://doi.org/10.1021/ma300213b

[57] Rafieian, Fatemeh, Mohammad Shahedi, Javad Keramat, and John Simonsen. "Mechanical, thermal and barrier properties of nano-biocomposite based on gluten and carboxylated cellulose nanocrystals." Industrial Crops and Products 53 (2014): 282-288. 
https://doi.org/10.1016/j.indcrop.2013.12.016

[58] Pesiri, David R., Betty Jorgensen, and Robert C. Dye. "Thermal optimization of polybenzimidazole meniscus membranes for the separation of hydrogen, methane, and carbon dioxide." Journal of Membrane Science 218, no. 1-2 (2003): 11-18. https://doi.org/10.1016/S0376-7388(03)00129-7

[59] Mundstock, Alexander, Sebastian Friebe, and Jürgen Caro. "On comparing permeation through Matrimid ${ }^{\circledR}$-based mixed matrix and multilayer sandwich FAU membranes: $\mathrm{H} 2 / \mathrm{CO} 2$ separation, support functionalization and ion exchange." International Journal of Hydrogen Energy 42, no. 1 (2017): 279-288.

https://doi.org/10.1016/i.ijhydene.2016.10.161

[60] Suzuki, Tomoyuki, and Yasuharu Yamada. "Effect of end group modification on gas transport properties of 6FDATAPOB hyperbranched polyimide-silica hybrid membranes." High Performance Polymers 19, no. 5-6 (2007): 553564.

https://doi.org/10.1177/0954008307081197 